\title{
Molecular characterisation of the CD79a and CD79b subunits of the B cell receptor complex in the gray short-tailed opossum (Monodelphis domestica) and tammar wallaby (Macropus eugenii): Delayed B cell immunocompetence in marsupial neonates
}

\author{
Louise Duncan ${ }^{\mathrm{a}, *}$, Koa Webster ${ }^{\mathrm{a}}$, Varun Gupta ${ }^{\mathrm{a}}$, Sham Nair ${ }^{\mathrm{a}}$, Elizabeth Deane ${ }^{\mathrm{b}}$ \\ a Department of Biological Sciences, Faculty of Science, Macquarie University, Eastern Road, North Ryde, NSW 2109, Australia \\ b The Chancellery, The Australian National University, Canberra, ACT 0200, Australia
}

\section{A R T I C L E I N F O}

\section{Article history:}

Received 26 May 2009

Received in revised form 15 March 2010

Accepted 16 March 2010

\section{Keywords:}

B cell receptor complex

CD79

cDNA cloning

Gene structure

Marsupial

Opossum

Tammar

\begin{abstract}
A B S T R A C T
The $\mathrm{B}$ cell receptor $(\mathrm{BCR})$ is a multiprotein complex that is pivotal to antigen recognition and signal transduction in B cells. It consists of an antigen binding component, membrane Ig ( $\mathrm{mIg})$, non-covalently associated with the signaling component, a disulphide-linked heterodimer of CD79a and CD79b. In this study, the gene and corresponding CDNA for CD79a and CD79b in the gray short-tailed opossum, as well as the cDNA sequences for CD79a and $\mathrm{CD} 79 \mathrm{~b}$ in the tammar wallaby, are described. Many of the structural and functional features of CD79a and CD79b were conserved in both marsupials, including the ITAM regulatory motif in the cytoplasmic tails of both subunits. The marsupial CD79 sequences shared a high degree of amino acid identities of 76\% (CD79a) and 72\% (CD79b) to each other, as well as $60-61 \%$ (CD79a) and 58-59\% (CD79b) with their eutherian counterparts. RT-PCR analysis of CD79a and CD79b transcripts in the immune tissues of tammar pouch young revealed $C D 79$ a transcripts in the bone marrow, cervical thymus and spleen at day 10 postpartum. CD79b transcripts were detected in the bone marrow and cervical thymus at day 10 but were not detected in the spleen until day 21 postpartum. These results suggest that a functional BCR may not be assembled until day 21 postpartum and the tammar neonate may not be capable of mounting an effective adaptive immune response until this time. The molecular information presented here will allow further investigation of the role of the CD79 subunits in marsupial B cell signaling, especially during ontogeny and disease.
\end{abstract}

(C) 2010 Elsevier B.V. All rights reserved.

\section{Introduction}

The mammalian CD79a (Ig- $\alpha)$ and CD79b (Ig- $\beta$ ) membrane proteins are expressed on $B$ cells as a disulphidelinked heterodimer that associates non-covalently with membrane Ig ( $\mathrm{mIg}$ ) to form the B cell receptor (BCR) complex, a multiprotein structure that is pivotal to antigen recognition and signal transduction in B cells (reviewed in

\footnotetext{
* Corresponding author. Tel.: +612 9850 9259; fax: +61 298509671 E-mail address: lduncan@bio.mq.edu.au (L. Duncan).
}

DeFranco, 1993; Reth, 1992). Whilst the mIg component is responsible for binding antigen, the cytoplasmic tail of the mIg heavy chain is very short and therefore incapable of transmitting activating signals to the inside of the cell. Thus, it is the CD79 subunits of the BCR that mediate these intracellular signaling events (Ales-Martinez et al., 1991; Reth et al., 1991). Like other signaling proteins (i.e. CD3 receptors and Fc receptors), the cytoplasmic tail of CD79a and CD79b contain an immuno-receptor tyrosine-based activation motif (ITAM) (Reth, 1989). In B cells, antigeninduced clustering of the BCR triggers the phosphorylation of the ITAM tyrosine residues on the CD79a and CD79b sub- 
units. This activity promotes the recruitment and activation of an array of effector molecules, of which Syk tyrosine kinase and BLNK (B cell linker protein) are most notable, forming a highly complex cascade of signaling pathways (reviewed in Dal Porto et al., 2004; Gold, 2002). In addition to its role in signaling, the CD79 subunits are essential for the transport and display of mIg molecules on the B cell surface (Matsuuchi et al., 1992).

In humans, the CD79a and CD79b glycoproteins are encoded by separate genes, namely $m b-1$ and $B 29$, and are localized on chromosome 19 and chromosome 17, respectively (Hashimoto et al., 1994b; Wood et al., 1993). Both of these genes encode proteins with a single extracellular Ig-like domain, a transmembrane region and a cytoplasmic tail. CD79 transcripts have been identified in a few mammals, including humans (CD79b, Hashimoto et al., 1993; CD79a, Yu and Chang, 1992), mice (CD79b, Hermanson et al., 1988; CD79a, Sakaguchi et al., 1988), rats (CD79b, Nakazato et al., 1998), cows (CD79a, Youn et al., 1996) and pigs (CD79a, Lee et al., 2008). In addition, a CD79b homolog has been identified in chickens (Katsukura et al., 2001), whilst recently, CD79a and b sequences have been isolated in some fish species (Guselnikov et al., 2003; Sahoo et al., 2008). Although antibodies raised against human CD79a and $b$ have identified cross-reactive proteins in marsupial tissues (Hemsley et al., 1995; Jones et al., 1993), nothing is known of these marsupial proteins or the genes encoding them.

We report here the isolation of CD79a and CD79b in two distantly related model marsupials, the gray short-tailed opossum (Monodelphis domestica) and the tammar wallaby (Macropus eugenii). Like all marsupials, these species are born after a short gestation of only 15 days in the opossum and 26 days in the tammar (Tyndale-Biscoe, 2005). Marsupials are highly altricial at birth and have no mature lymphoid tissues (Deane and Cooper, 1988). The ability of the neonate to survive outside the sterile uterine environment with no functional immune system is of great interest. Identifying the collection of immune related genes that regulate host immunity in marsupials may shed light on the processes involved in protecting the vulnerable neonate, information that is not available from their eutherian counterparts. Our work in this area has been facilitated by the release of the first marsupial genome sequence data of the opossum (Mikkelsen et al., 2007). Using this information, we have focused on the characterisation of key molecular components of the adaptive immune system in marsupials. We recently reported the cloning of the $\mathrm{T}$ cell markers, CD4 (Duncan et al., 2007) and CD8 (Duncan et al., 2009), in the opossum and the tammar wallaby. These studies revealed conservation of many of the hallmarks of their eutherian homologs, including a regulatory motif and the presence in the marsupial promoter regions of several potential transcription factor-binding sites known to be important for promoter function in the eutherian $C D 4$ and CD8 genes.

In order to further our analysis of lymphoid cell marker genes in marsupials we have cloned the B cell markers CD79a and CD79b. To this end, the opossum genome sequence data was used to (i) identify the genomic organization of the opossum $C D 79 a$ and $C D 79 b$ genes, (ii) isolate the full-length CD79a and CD79b cDNAs in the opossum as well as in the tammar wallaby and (iii) analyse the expression of CD79a and CD79b gene transcripts in opossum (adult) and tammar tissues from pouch young to adulthood. The information reported here provides the first gene sequence information for B cell markers in marsupials and will assist in the elucidation of the molecular processes involved in B cell signaling in marsupials, a process known to be crucial for the differentiation, proliferation and survival of B cells in their eutherian relatives.

\section{Materials and methods}

\subsection{Opossum CD79a and CD79b gene annotation}

The $M$. domestica whole genome sequence data released from the Broad Institute was accessed through the Ensembl database (www.ensembl.org/Monodelphis domestica/index.html). The putative opossum CD79a gene sequence was obtained from the MonDom0.5 Ensembl assembly (the preliminary assembly available temporarily on the Ensembl Pre-build site) and the putative opossum $C D 79 b$ gene sequence was obtained from the MonDom5.0 Ensembl assembly by BLASTN search (using the default search parameters) using the human CD79a and CD79b cDNA sequences (GenBank accession nos. M74721 and S52229, respectively) as query. The putative opossum $C D 79 a$ and $C D 79 b$ Ensembl gene models were used to design primers for PCR analysis and cloning of the opossum and tammar CD79a and CD79b cDNA sequences.

\subsection{Animal tissues and $c D N A$ preparation}

Opossum tissues (spleen, liver, kidney, lung, heart, brain and gut) from a 4-month-old male animal were supplied by the Department of Pharmacology, University of Melbourne, Victoria, Australia. Tammar wallaby tissues from adult (spleen, liver, kidney, lung, heart, brain, gut and blood) and pouch young (bone marrow, cervical thymus, spleen, lung, gut, and blood) were collected opportunistically from animals housed at the Macquarie University Fauna Park (North Ryde, NSW, Australia) and CSIRO, Sustainable Ecosystems (Canberra, Australia) that had been euthanized as part of other approved experimental work or as approved by the Macquarie University Animal Ethics committee (Approval Nos. 2006/002, 2007/030). The age of the tammar pouch young was estimated from head length measurements (Poole et al., 1991). Total RNA was isolated using TRI reagent (Molecular Research Centre, OH, USA) following the manufacturer's instructions. cDNA for RT-PCR was synthesised using SuperScript II reverse transcription system using oligo(dT) primers (Invitrogen, CA, USA) and RACE-ready first-strand cDNA was synthesised from opossum and tammar spleen tissue using the SMART RACE cDNA amplification kit (BD Biosciences Clontech, CA, USA) according to the manufacturer's protocol.

\subsection{Cloning of opossum and tammar CD79a and CD79b cDNA}

To confirm the putative opossum CD79 sequences, opossum CD79a and CD79b cDNA sequences were iso- 
Table 1

Primer sequences.

\begin{tabular}{|c|c|c|c|}
\hline Primer name & Sequence $5^{\prime}-3^{\prime}$ & Location $^{\mathrm{a}}$ & Application \\
\hline OpCD79aF1 & CCAGTGTCGGGTCTCCATCAGGG & Opossum 335-357 & CD79a 3'RACE PCR \\
\hline OpCD79aR1 & CCCTGATGGAGACCCGACACTGG & Opossum 335-357 & CD79a 5'RACE PCR \\
\hline OpCD79aF2 & AGTGTCGGGTCTCCATCA & Opossum 337-354 & Tissue expression \\
\hline OpCD79aR2 & AGCGTATTTCTCATTCTGCCA & Opossum 528-548 & Tissue expression \\
\hline TamCD79aF1 & TCCTGYGGBACBTACCTCMG & Tammar 392-411 & CD79a RT-PCR \\
\hline TamCD79aR1 & GMRCAGTCRTCVAGGTTMAG & Tammar 611-630 & CD79a RT-PCR \\
\hline TamCD79aF2 & CGTGAGCCAATACCCAGACCCTTC & Tammar 416-439 & CD79a 3'RACE PCR \\
\hline TamCD79aR2 & GAAGGGTCTGGGTATTGGCTCACG & Tammar 416-439 & CD79a 5'RACE PCR \\
\hline TamCD79aF3 & ACTGCGAACACGATGGGA & Tammar 198-215 & Tissue expression \\
\hline TamCD79aR3 & GGTCTGGGTATTGGCTCAC & Tammar 417-435 & Tissue expression \\
\hline OpCD79bF1 & СTCATCATTGTCTTCATCACGGTCCC & Opossum 544-569 & CD79a 3'RACE PCR \\
\hline OpCD79bR1 & GGGACCGTGATGAAGACAATGATGAG & Opossum 544-569 & CD79a 5'RACE PCR \\
\hline OpCD79bF2 & CAAAGAAGGGCTGGGTGTG & Opossum 66-84 & Tissue expression \\
\hline OpCD79bR2 & CCGTGATGAAGACAATGATGAG & Opossum 544-565 & Tissue expression \\
\hline TamCD79bF1 & AGCRGMGGAACACVCTGAA & Tammar 517-535 & CD79b RT-PCR \\
\hline TamCD79bR1 & TCYTGGCCTGGRTGCTCDC & Tammar 730-748 & CD79b RT-PCR \\
\hline TamCD79bF2 & CTCATCATTGTCTTCATCACCGTCCC & Tammar 564-589 & CD79b 3'RACE PCR \\
\hline TamCD79bR2 & GGGACGGTGATGAAGACAATGATGAG & Tammar 564-589 & CD79b 5'RACE PCR \\
\hline TamCD79bF3 & ACACCGCCACTCTCATCATC & Tammar 367-386 & Tissue expression \\
\hline TamCD79bR3 & ССАССТTGСТСТСАТССТТАТС & Tammar 606-627 & Tissue expression \\
\hline
\end{tabular}

Note: $\mathrm{Y}=\mathrm{C} / \mathrm{T}, \mathrm{B}=\mathrm{C} / \mathrm{G} / \mathrm{T}, \mathrm{M}=\mathrm{C} / \mathrm{A}, \mathrm{R}=\mathrm{A} / \mathrm{G}, \mathrm{V}=\mathrm{G} / \mathrm{A} / \mathrm{C}, \mathrm{D}=\mathrm{T} / \mathrm{G} / \mathrm{A}$.

a Primer location in opossum CD79a cDNA (FJ817077), tammar CD79a cDNA (FJ817078), opossum CD79b cDNA (FJ817079) and tammar CD79b cDNA (FJ817080).

lated by RACE PCR using gene-specific primers that were designed based on the annotated opossum CD79 sequences. The primers used for amplifying the tammar CD79a and CD79b cDNA sequences were degenerate and were designed from an alignment of known eutherian CD79 sequences and the annotated opossum CD79a and CD79b genomic DNA. The primer sequences are listed in Table 1 . Initially tammar cDNA fragments were amplified from spleen tissue using primers TamCD79aF1 and TamCD79aR1 or TamCD79bF1 and TamCD79bR1 for the CD79a and CD79b sequences, respectively. The PCR amplifications were performed using a touchdown protocol as follows: initial denaturation at $94^{\circ} \mathrm{C}$ for $2 \mathrm{~min}$ followed by 35 cycles of denaturation at $94^{\circ} \mathrm{C}$ for $30 \mathrm{~s}$, an annealing temperature commencing at $55^{\circ} \mathrm{C}$ and then decreasing by $0.5^{\circ} \mathrm{C}$ per cycle down to $40^{\circ} \mathrm{C}$, and extension at $72^{\circ} \mathrm{C}$ for 30 s. A final elongation step was carried out at $72^{\circ} \mathrm{C}$ for $5 \mathrm{~min}$.

The opossum and tammar CD79a RACE products were amplified using the primers OpCD79aF1 or TamCD79aF2 for 3' RACE and OpCD79aR1 or TamCD79aR2 for 5' RACE PCR. Similarly, the opossum and tammar CD79b RACE products were amplified using the primers OpCD79bF1 or TamCD79bF2 for 3' RACE and OpCD79bR1 or TamCD79bR2 for 5' RACE PCR. PCR reactions were performed in conjunction with RACE PCR primers provided with the kit and BD Advantage 2 polymerase mix using a touchdown program as follows: 5 cycles of $94^{\circ} \mathrm{C}$ for $30 \mathrm{~s}$ and $72{ }^{\circ} \mathrm{C}$ for $2 \mathrm{~min}$ followed by 5 cycles of $94^{\circ} \mathrm{C}$ for $30 \mathrm{~s}, 70^{\circ} \mathrm{C}$ for $30 \mathrm{~s}$ and $72^{\circ} \mathrm{C}$ for $2 \mathrm{~min}$, then 30 cycles of $94^{\circ} \mathrm{C}$ for $30 \mathrm{~s}, 68^{\circ} \mathrm{C}$ for $30 \mathrm{~s}$ and $72^{\circ} \mathrm{C}$ for $2 \mathrm{~min}$. A final elongation step was carried out at $72{ }^{\circ} \mathrm{C}$ for $7 \mathrm{~min}$. PCR products were purified using the Wizard SV gel and PCR clean-up system (Promega, WI, USA) and cloned into the pCR2.1 vector (Invitrogen, CA, USA). Clones were sequenced on a 3130xl DNA Capillary Sequencer (Applied Biosystems, CA, USA) at Macquarie University.

\subsection{Sequence data analysis}

The opossum CD79a genomic sequence was obtained by megaBLAST of the $M$. domestica trace archive at NCBI using the opossum cDNA sequence as query whilst the opossum $C D 79 b$ genomic sequence was obtained from the Ensembl database. The genomic organisation of the opossum $C D 79 a$ and $C D 79 b$ genes were determined by aligning the genomic sequence and the experimentally derived cDNA sequence using the Spidey program at NCBI (http://www.ncbi.nlm.nih.gov/spidey/). These opossum $C D 79 a$ and $C D 79 b$ genomic sequences also contained the $5^{\prime}$ flanking region of the gene for promoter analysis. The region upstream of the tammar $C D 79 a$ and $C D 79 b$ genes were obtained by megaBLAST of the $M$. eugenii trace archive at NCBI using the tammar cDNA sequences as query. These sequences were used for promoter analysis. The putative promoter region for the opossum and tammar $C D 79 a$ and $C D 79 b$ genes were analysed using TFsearch (www.cbrc.jp/research/db/TFSEARCH.html). The opossum and tammar CD79a and CD79b cDNA sequences were analysed using a number of programs available through the BioManager database at the Australian National Genomic Information Service (ANGIS). Multiple sequence alignments were performed using ClustalW and displayed using Genedoc (psc.edu/biomed/genedoc). Putative signal peptide cleavage sites for the amino acid sequences were predicted using the SignalP program (www.cbs.dtu.dk/services/SignalP) and domain boundaries were predicted using Interproscan (www.ebi.ac.uk/interproscan). Phylogenetic trees were drawn from the amino acid sequence alignment using the PHYLIP group of programs (Felsenstein, 1989), accessed via BioManager. The phylogenetic tree was displayed using the Treeview program (Page, 1996) and the bootstrap method was used to indicate confidence values for tree nodes based on 100 replicates. 


\subsection{Expression of CD79a and CD79b transcripts in opossum and tammar tissues}

Total RNAs and cDNAs from adult opossum and tammar tissues as well as tammar pouch young tissues (days $10,21,60$, and 120 postpartum) were prepared. For analysing expression in opossum tissues, the primer sequences were OpCD79aF2 and OpCD79aR2 or OpCD79bF2 and OpCD79bR2 for CD79a and CD79b, respectively. The expression of tammar CD79a and CD79b was analysed using the primer sequences TamCD79aF3 and TamCD79aR3 or TamCD79bF3 and TamCD79bR3, respectively. The primer sequences are listed in Table 1 . Expression of the house-keeping gene G3PDH was documented as an internal control. The RT-PCR reactions were performed using $2.5 \mathrm{mM} \mathrm{MgCl}_{2}$ and Flexi-Taq DNA polymerase (Promega, WI, USA) under the following conditions: initial denaturation at $94^{\circ} \mathrm{C}$ for 2 min followed by 35 cycles of denaturation at $94{ }^{\circ} \mathrm{C}$ for $30 \mathrm{~s}$, annealing for $30 \mathrm{~s}$ at $60^{\circ} \mathrm{C}$ for opossum and tammar CD79a and CD79b and $55^{\circ} \mathrm{C}$ for $\mathrm{G} 3 \mathrm{PDH}$, and elongation at $72^{\circ} \mathrm{C}$ for $30 \mathrm{~s}$. A final elongation was carried out at $72^{\circ} \mathrm{C}$ for 5 min.

\section{Results and discussion}

\subsection{Marsupial CD79a and CD79b cDNA sequences}

The full-length opossum CD79a cDNA sequence (Fig. 1A, GenBank accession no. FJ817077) and the tammar CD79a cDNA sequence (Fig. 1B, GenBank accession no. FJ817078) consisted of 1041 and 1195 nucleotides, respectively. Both sequences included an identical polyadenylation signal (AATAAA). In both marsupial sequences, the 660 nucleotide long open reading frame translated into a predicted polypeptide of 219 amino acid residues, initiated from the first 5'-proximal ATG codon (Kozak, 1983). The CD79a protein had a predicted molecular weight of $24 \mathrm{kDa}$ in both marsupials. Cleavage of the signal peptide, predicted to be 23 amino acids long in both marsupials, would generate a mature polypeptide of 196 residues.

The full-length opossum CD79b cDNA sequence (Fig. 2A, GenBank accession no. FJ817079) and the tammar CD79b cDNA sequence (Fig. 2B, GenBank accession no. FJ817080) consisted of 1431 and 1420 nucleotides, respectively and included an identical polyadenylation signal (AATAAA) in both sequences. The open reading frame which is 696 nucleotides in length in both marsupial sequences, translated into a predicted polypeptide of 231 amino acid residues, initiated from the first 5'-proximal ATG codon (Kozak, 1983). The marsupial CD79b polypeptides both had a predicted molecular weight of $26 \mathrm{kDa}$. Cleavage of the signal peptide, predicted to be 29 residues in the opossum and 34 residues in the tammar, would generate a mature polypeptide of 202 residues and 197 residues, respectively.

\subsection{Genomic organisation of the opossum CD79a gene}

A putative opossum CD79a homolog was identified by BLASTN search of the Ensembl MonDom genome sequence data using the human CD79a cDNA sequence as the query. Although a putative opossum CD79a gene model was first identified on the Ensembl MonDom0.5 assembly, attempts to identify this sequence data on ensuing Monodelphis genome assemblies (versions 2.0, 4.0, 5.0) were unsuccessful. The putative MonDom0.5 opossum CD79a gene model contained 606 nucleotides which defined 4 exons that were homologous to exons 2-5 of the human CD79a gene. Interestingly, analysis of the subsequent MonDom assemblies using the experimentally derived opossum CD79a cDNA sequence revealed only a small section of the opossum CD79a gene (exon 1 and a part of intron 1) that was located in a region of unaligned contigs that have not been anchored to a chromosome in the final assembly. Although the syntenic relationship of the opossum CD79a gene to its eutherian homologs could not be determined, it is interesting to note that exon 1 of the opossum CD79a gene was located directly upstream of the gene RPS19 (40S ribosomal protein S19) as is the human CD79a gene on chromosome 19q13 (Hashimoto et al., 1994b).

Even though the full-length genomic sequence was missing from the Ensembl genome assemblies, analysis of the trace archive at NCBI showed full alignment of the entire opossum CD79a cDNA sequence with the traces, and this data was used to determine the putative genomic structure of the opossum CD79a gene (shown in detail and schematically in Figs. 1A and 3A, respectively). The opossum CD79a gene displayed remarkable similarity in exon structure to its human homolog (Ha et al., 1994). Both genes contained 5 exons that were identical in size (except exon 1 which is 7 residues shorter in the opossum) and were conserved in their sequences and locations of their exon/intron boundaries. Introns 1 and 2 contained the type I (also known as phase I) splice motif and introns 3 and 4 were the type 0 (phase 0 ) motif. This is in agreement with the introns of the CD79a gene in humans (Ha et al., 1994), mice (Kashiwamura et al., 1990) and cows (Youn et al., 1997). As in the eutherian CD79a genes, each exon of the opossum CD79a gene roughly encoded the structural domains of the predicted polypeptide with the exception of the cytoplasmic tail, which is encoded by two exons (Fig. 3A). In summary, exon 1 encoded the first 19 amino acids of the leader peptide whilst exon 2 coded for the remainder of the leader peptide (4 amino acids) and most of the Ig domain (96 amino acids). The rest of the Ig domain (17 amino acids), the entire transmembrane region (21 amino acids) and 2 amino acids of the cytoplasmic tail are encoded on exon 3 and the remainder of the cytoplasmic tail is divided between exons 4 and 5 (23 amino acids and 37 amino acids, respectively).

\subsection{Genomic organisation of the opossum CD79b gene}

The putative opossum $C D 79 b$ gene identified on Chromosome 2 (at location 211,162,801 bp) of the Ensembl MonDom5.0 assembly was situated at a distance of $17.6 \mathrm{~kb}$ upstream of the $\mathrm{GH}$ gene cluster (growth hormone) and $12.4 \mathrm{~kb}$ downstream of the SCN4A gene (skeletal muscle Na-channel), arranged in a head-to-tail configuration in the same transcriptional orientation. This chromosomal arrangement showed highly conserved synteny with human chromosome 17q23 (Bennani-Baiti et al., 1998), though the GH and SCN4A genes are more closely posi- 
(A) 1 ACGGGCAGACGGCACACTCTTTCCCAAGCACTGTGCCAGCCGGG

45 ATg ATG CCC GGC CTG AGC CTG CCC TGC GCC CTT CTC CTC GTC TCT GCC CTG AgC CCT G gtaggt...

$\begin{array}{lllllllllllllllll} & \text { L } & \text { S } & \text { L } & \text { P } & \text { C } & \text { A } & \text { L } & \text { L } & \text { L } & \text { V } & \text { S } & \text { A } & \text { L } & \text { S } & \text { P } & I\end{array}$

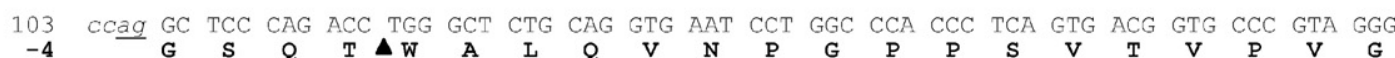

165 GGC ATA GCC CAG CTG CCC TGT GAA CAC GAC GGG GGC CCC AAT GCC AAC GTG ACT TGG TGG CGA GTC

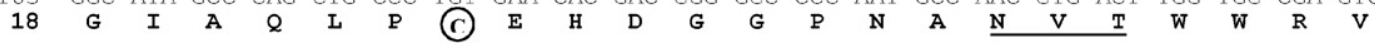

231 ATT TTG GGC AAC TTC TCA TGG CCC AAA GTC CAG GTG GCG AAG GAG TCT GAG CTC AAT GGG ACC CTG

$\begin{array}{llllllllllllllllllllllll}40 & I & I & G & N & F & S & W & P & K & V & Q & V & A & K & E & S & E & L & \underline{N} & G & T & I\end{array}$

297 ATC CTC TGG GGA GTG AAA AAG AGC GAT GGA GGC GTC TAC CAG TGT CGG GTC TCC ATC AGG GGC AAC

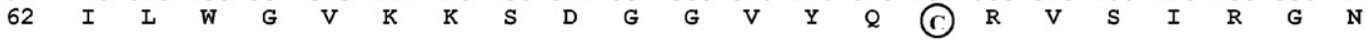

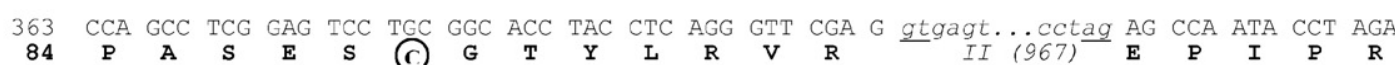

417 CCC TTC CTG GAC ATG GGA GAG GCC ACC AAG AAC AGG ATT ATC ACT GCA GAG GGA ATC ATT CTG CTT

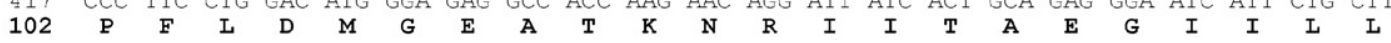

483 TTC TGC GCT GTC GTC CCG GGG ACC CTC CTG CTC TTC AGA gtaaga...ctgtag AAG CGG TGG CAG AAT

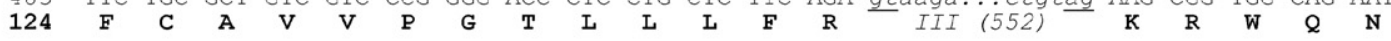

537 GAG AAA TAC GCT GTG GAC CAC CTG GAC TAC TAT GAT GAT GAG AAC CTG TAT GAG gtgaga...ctcCag

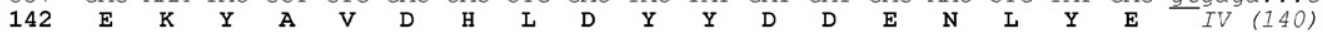

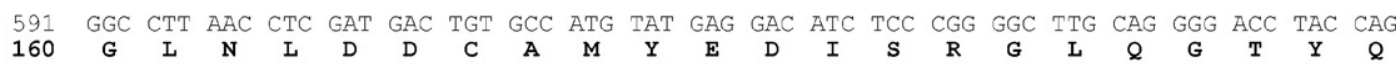

657 GAT GCC ACC ACC CTC AGg GTG GGG GAT GTC CAG CTG GAg AAg CCG TGA

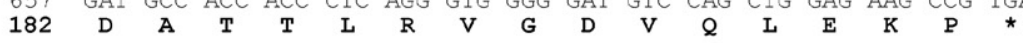

705 GGGCCCTGCGTGAAGTCTCTAGCTTCGACCTGCCTTAACCTGCCCCGTTTAGGTCTTCTGACTTGTCCCGCTCTCCGTCTCCTCGGG 792 ACCAGATGGTTTCCAAGGTCCTTCCCAGCTCTGATGTTCCATGTTCCTAAATCTGTCCCCTTTGCCCTCTCCTCCCCTCCCTTCCTG

879 GCCCTTACTTCTAACTTGCTCCCCCGTAATCCAGGAGATGCCTGAAGCAGGATCCCCCCAAAGCCCCCCAAGCTTTGTCATGGCCAC

966 TAATGATCTATAAATGTGGGCCCGTTGGAAGAAGGGGTCCATTCGCAGCAAAAAAAAAAAAAAAAAAAAAAA

(B) 1 AgGCAAAGACAGCTCTCCTTTTTCCACAGCACGATCTCAGCTAGTTGGGGACCCTTTGGGG

62 ATg ATG TCC AGC CTC ATT CCG CCC TTG GTC CTG CTC CTC ATC TCT GTT CTG AAC CCT GGC TTC CTC

$\begin{array}{llllllllllllllllllllllll}-23 & M & M & \text { S } & \text { S } & \text { L } & \text { I } & \text { P } & \text { P } & \text { L } & \text { V } & \text { L } & \text { L } & \text { L } & \text { I } & \text { S } & \text { V } & \text { L } & \text { N } & \text { P } & G & \text { F } & \text { L }\end{array}$

128 ACC TGG GGT CTG AGA GTG GAG CCT GGC CAG CCC TCC GTG ACT GTG CCT GTG GGG GGC ACG GCC CTG

1 T $\mathbf{L}$ G $L$

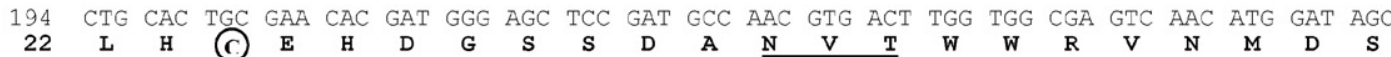

260 TTC ACA TGG CCC AGg AAA AAg GTG GAg AAA TTC ATT CAT CCC AAT GGG ACA CTG GTC ATC TTG GCA

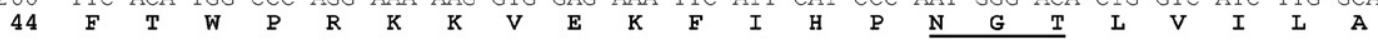

326 GCA AAC AAG AGC GAC GGA GGC ATG TAC CTA TGT CAA GTT TCT GTC GAG AAT GAT CAA GCC TCA GAG

$\begin{array}{llllllllllllllllllllllll}6 & \mathrm{~A} & \mathrm{~N} & \mathrm{~K} & \mathrm{~S} & \mathrm{D} & \mathrm{G} & \mathrm{G} & \mathrm{M} & \mathrm{Y} & \mathrm{L} & \mathrm{C} & \mathrm{Q} & \mathrm{V} & \mathrm{S} & \mathrm{V} & \mathrm{E} & \mathrm{N} & \mathrm{D} & \mathrm{Q} & \mathrm{A} & \mathrm{S} & \mathrm{E}\end{array}$

392 TCC TGT GGC ACC TAC CTC AGg GTT CGT GAG CCA ATA CCC AGA CCC TTC TTG GAC ATG GGC GAA GGC

$\begin{array}{llllllllllllllllllllllll}88 & \mathrm{~S} & \mathrm{C} & \mathrm{G} & \mathrm{T} & \mathrm{Y} & \mathrm{L} & \mathrm{R} & \mathrm{V} & \mathrm{R} & \mathrm{E} & \mathrm{P} & \mathrm{I} & \mathrm{P} & \mathrm{R} & \mathrm{P} & \mathrm{F} & \mathrm{L} & \mathrm{D} & \mathrm{M} & \mathrm{G} & \mathrm{E} & \mathrm{G}\end{array}$

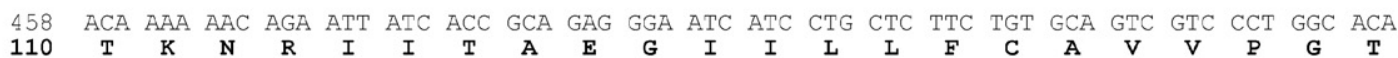

524 CTG CTG CTC TTT AGG AAg CGT TGG CAG AAT GAG AGA TAT GCT GTG GAT CAC TTG GAC TAT TAT GAT

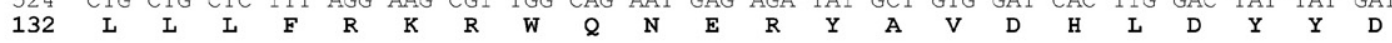

590 GAT GAG AAC CTA TAT GAG GGT CTT AAC CTC GAT GAC TGC GCC ATG TAT GAG GAC ATC TCC CGG GGT

$\begin{array}{lllllllllllllllllllllllllllll}154 & \mathrm{D} & \mathrm{E} & \mathrm{N} & \mathrm{L} & \mathrm{Y} & \mathrm{E} & \mathrm{G} & \mathrm{L} & \mathrm{N} & \mathrm{L} & \mathrm{D} & \mathrm{D} & \mathrm{C} & \mathrm{A} & \mathrm{M} & \mathrm{Y} & \mathrm{E} & \mathrm{D} & \mathrm{I} & \mathrm{S} & \mathrm{R} & \mathrm{G}\end{array}$

656 CTG CAG GGg ACC TAC CAG GAT GCC ACT ACC CTC AGg GTg GgA GAT GTC CAG CTA GAG AAG CCA TGA

$\begin{array}{llllllllllllllllllllllllllll}176 & \mathrm{~L} & \mathrm{Q} & \mathrm{G} & \mathrm{T} & \mathrm{Y} & \mathrm{Q} & \mathrm{D} & \mathrm{A} & \mathrm{T} & \mathrm{T} & \mathrm{L} & \mathrm{R} & \mathrm{V} & \mathrm{G} & \mathrm{D} & \mathrm{V} & \mathrm{Q} & \mathrm{L} & \mathrm{E} & \mathrm{K} & \mathrm{P} & *\end{array}$

722 TGGCCCTTCCTGGCCCTGCTCAAAGCAGCCTCCCTCCCTTAAACTGCCCCCTTCAGGTCTTTCTGACTGTCCCACTCTCAGTTTCCT

809 CAGGAGTCAGTTTGACTAGATGGTATCTAAGGCCCCTCCCAGCCCTGACATCCCCTGTTCCAAGGCCCCTCCCAGCTTTGATATTCC

896 CTGTTCCAAGATCCCTCCCAGCTCTGATATTTCATGTTCTGTTTCCACGTTTGACATGTTTTCCTCTCTCCCATGATATGCCCCCTT

983 CTCTATCCCCCTCATGCCTTGACTCCTGATCCCTTTTAACTTTCTCCCCTATAACTCTTTCCCTATAATGCAGGAGGTGCTTGAAGC

1070 AGGATCCCTCCCCCTAAGTTTTGTTATAGCTACTAATGATAATAAATCTGTGGCCCATGGGGAAGGAAAGGGTTCCATTCTCCATTG

1157 GGGGGATGGTAAAAAAAAAAAAAAAAAAAAAAAAAAAA

Fig. 1. The nucleotide sequence (numbered at the top) and deduced amino acid sequence (one-letter abbreviation code, numbered below in bold) for CD79a in the opossum (A) and the tammar wallaby (B). The location of the introns in the opossum sequence are shown in italics (gt/ag sites in italics and underlined; intron number in roman numerals and length of intron in parentheses. For intron 1 the length is designated unk for unknown). For both sequences, the predicted mature polypeptide begins at position +1 indicated with a filled arrowhead. Extracellular cysteine residues are circled. Potential $\mathrm{N}$-linked glycosylation sites are underlined and the polyadenylation signal is double underlined. 
tioned to the $C D 79 b$ gene in human at 9.7 and $8.2 \mathrm{~kb}$, respectively. The putative MonDom5.0 opossum $C D 79 b$ gene model contained a predicted cDNA transcript length of 573 nucleotides divided amongst 4 exons which corresponded to exons 3-6 of the human $C D 79 b$ gene. Previous MonDom genome assemblies (versions 2.0 and 4.0) predicted identical gene models for the opossum $C D 79 b$ but were unable to identify the locations of exons 1 and 2. Furthermore, gene prediction software (Genscan and Genewise) were also unable to successfully identify these exons. Therefore, the partial Ensembl opossum $C D 79 b$ sequence was used to design primers to isolate the full-length opossum cDNA sequence by RACE PCR. This experimentally derived CDNA sequence was aligned with the Ensembl genomic sequence to inform the genomic organization of the opossum $C D 79 b$ gene (shown in detail in Fig. 2A and schematically in Fig. 3B).
The opossum $C D 79 b$ gene spanned $13 \mathrm{~kb}$ and was much larger than its $C D 79 b$ homologs in humans, rats and chickens, which are $3.8,3.1$ and $4.3 \mathrm{~kb}$ in length, respectively (Hashimoto et al., 1994a; Katsukura et al., 2001; Nakazato et al., 1998). The vast size of the opossum $C D 79 b$ gene was due to larger intronic lengths, which totalled $12.3 \mathrm{~kb}$ compared to only $2.3 \mathrm{~kb}$ in human $C D 79 \mathrm{~b}$. In contrast, the length of the six exons in the human and opossum $C D 79 b$ genes were well conserved, with the exception that exon 2 in opossum $C D 79 b$ is 3 nucleotides longer than its human homolog. This conservation of exon structure also extended to the sequences and locations of the exon/intron boundaries, resulting in an identical structural domain arrangement in the predicted opossum polypeptide and the human CD79b protein (Fig. 3B). Thus, exon 1 encoded the first 22 amino acids of the leader peptide. Exon 2 encoded the rest of the leader peptide ( 7 amino

(A)

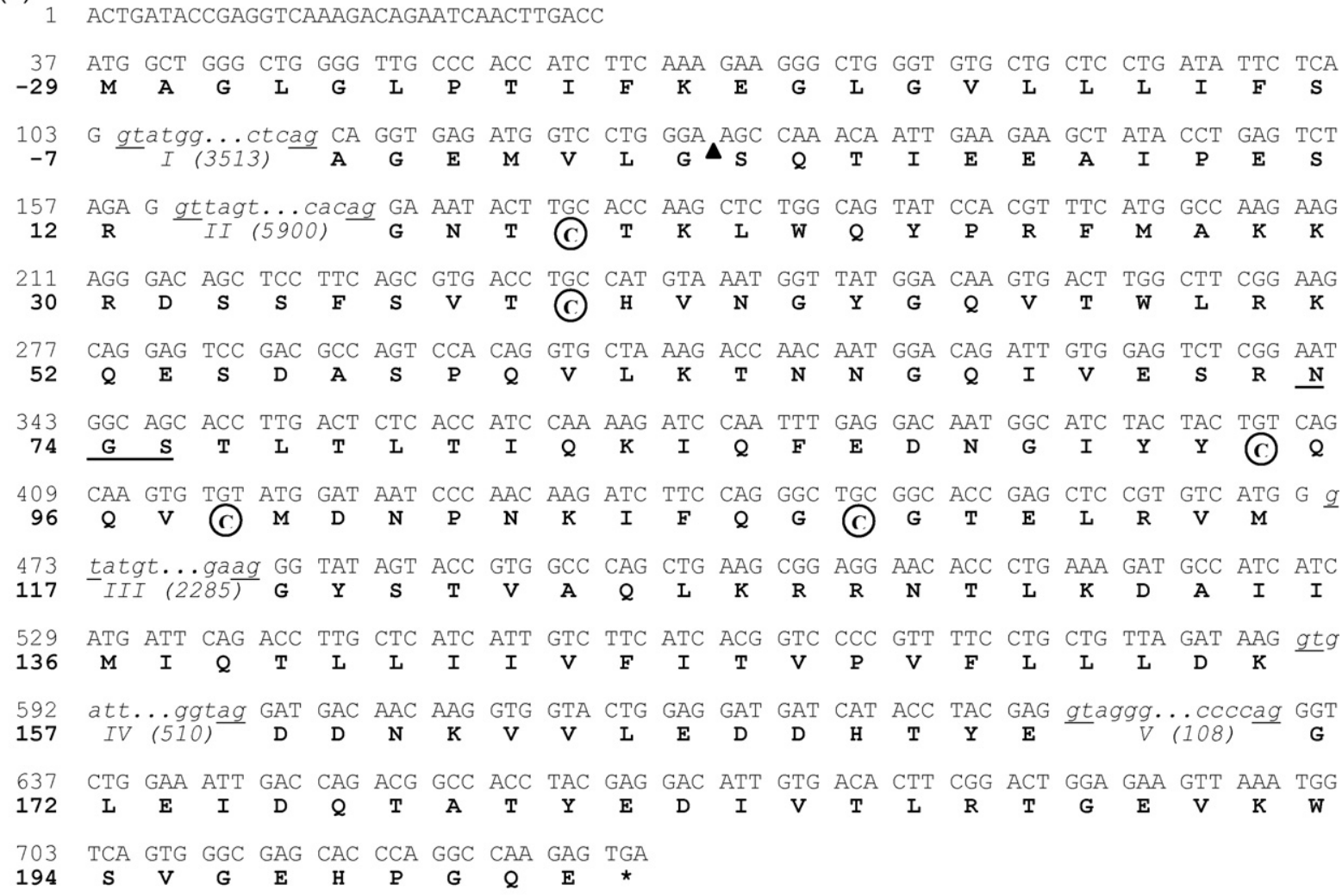

733 AGGCTTCCCCCATCTGATGATCCTTCCCATGCTCCCCATCTCTCCACCAACCTTCTGGAGAGAACTCATCCAGCTACTCAGCTTCAT 820 GGACCTGTTCTGGTTCCCAGCCCGAAACGCCTTTCTCCTCTACCTATAACTGTCCCATAACTGTCCCACCTCCAGGCTTACTGGCCC 907 AGTTCTGCCTTCCTACCGCCAATCCCTCTCACCTCACAACCATCTCCAGAGGGATATAGGCCTGCAGGGTTTAACAGAACACAGCTT 994 TAAGGAAAGTTATCCCTGGAAGGCTCTTTGGAGTTGGCCATGTTTGGGATGGCTGGGGTTGGGAGGAGATAGAGTAGAGAGAGACCC 1081 AGACCTGGGGGGGAGAGGGGAGGTAAGGCAAAGAAAAACAGAGATTTGAAGTCTAGTGAAGAAGAAAGGGAGGAAACCTGTAAATCT 1168 GACTCAGATGGACCTAGAAGACCAGGCCATACTTGAATCCCTACAGTATCATTCCTCCAGTCCTAATGAAAGCCAGGACCAGGAGAG 1255 ACTCTGAACACTTGGCCGGCCAATTGACTCAATCCAAATTGGGGGTTATGGAAATATATCCCCTTCTCCCATCTTCCAGGGACTTAT 1342 TGAGCCTTTCTTGGTGTCCTGTGCATAGCCTTTGATGTAATAAACTGTGTGTTTTGAGAAAACACAAAAAAAAAAAAAAAAAAAAAA 1429 AAA

Fig. 2. The nucleotide sequence (numbered at the top) and deduced amino acid sequence (one-letter abbreviation code, numbered below in bold) for CD79b in the opossum (A) and the tammar wallaby (B). The location of introns in the opossum sequence is shown in italics (gt/ag sites in italics and underlined; intron number in roman numerals and length of intron in brackets). The predicted mature polypeptide begins at position +1 indicated with a filled arrowhead. Extracellular cysteine residues are circled. Potential N-linked glycosylation sites are underlined and the polyadenylation signal is double underlined. 
(B)

\section{AAgGAACCACAGCCACGGAGGTCAAGGCCTGGGTCAAGGACAGAATCAATTTGACC}

57 ATG GCT GgG CTG GGg CTG CCC ACC ATC TCC AAA GAA GGA CTG AGA GTG CTG CTC CTG ATA CTA TCA

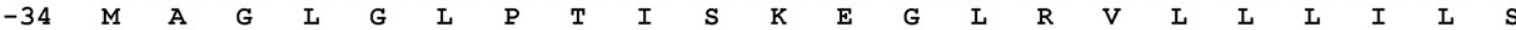

123 GGT GAG ATG ATC CTG AAA GTC CAA ACA GCG AAT GGT GAT GTT GTC CAG GCT TCT AGA GCA AAT TCA

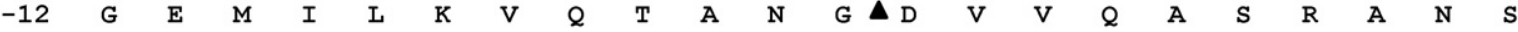

189 TGC AGC AAG TTA TGG CAA CGT CTA CGT TTT GTG GCC AAA AAG AGG GAC AGC TCC TTC GAA GTG ACC $\begin{array}{lllllllllllllllllllllll}11 & C & S & K & L & W & Q & R & L & R & F & V & A & K & K & R & D & S & S & F & E & V & T\end{array}$

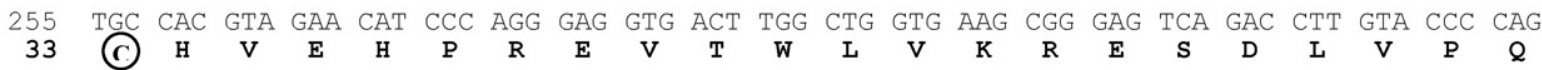
3

GCC CTT CCA CCC GAT AAT GGA CGT CTA AGG CGG GTG ACA AAC AAC AAC ACC GCC ACT CTC ATC ATC $\begin{array}{lllllllllllllllllllllll}\mathrm{A} & \mathrm{L} & \mathrm{P} & \mathrm{P} & \mathrm{D} & \mathrm{N} & \mathrm{G} & \mathrm{R} & \mathrm{L} & \mathrm{R} & \mathrm{R} & \mathrm{V} & \mathrm{T} & \mathrm{N} & \mathrm{N} & \mathrm{N} & \mathrm{T} & \mathrm{A} & \mathrm{T} & \mathrm{L} & \mathrm{I} & \mathrm{I}\end{array}$ ACA AAg ATA CAA TTT GAG GAC AAT GGC ATC TAT TAT TGT GAA GAA AAg TGT ATG GAA GGT CCT AGA $\begin{array}{lllllllllllllllllllllllll}\text { T } & \text { K } & \text { I } & Q & \text { F } & \text { E } & \text { D } & \text { N } & \text { G } & \text { I } & \text { Y } & \text { Y } & \text { C } & \text { E } & \text { E } & \text { K } & \text { C } & \text { M } & \text { E } & \text { G } & \text { P } & \text { R }\end{array}$ GAG AAC CTC CGG GGC TGT GGC ACT GAg CTG CGT GTC ATG GGC TTC AgC ACT ATG GCC CAG CTG AAG $\begin{array}{lllllllllllllllllllllll}\mathbf{E} & \mathrm{N} & \mathrm{L} & \mathrm{R} & \mathrm{G} & \mathrm{C} & \mathrm{G} & \mathrm{T} & \mathrm{E} & \mathrm{I} & \mathrm{R} & \mathrm{V} & \mathrm{M} & \mathrm{G} & \mathrm{F} & \mathrm{S} & \mathrm{T} & \mathrm{M} & \mathrm{A} & \mathrm{Q} & \mathrm{L} & \mathrm{K}\end{array}$ CGG AGg AAC ACT CTG AAA GAT GCC ATT ATT ATG GTC CAg ACC CTA CTC ATC ATT GTC TTC ATC ACC $\begin{array}{llllllllllllllllllllll}\mathrm{R} & \mathrm{R} & \mathrm{N} & \mathrm{T} & \mathrm{L} & \mathrm{K} & \mathrm{D} & \mathrm{A} & \mathrm{I} & \mathrm{I} & \mathrm{M} & \mathrm{V} & \mathrm{Q} & \mathrm{T} & \mathrm{L} & \mathrm{I} & \mathrm{I} & \mathrm{I} & \mathrm{V} & \mathrm{F} & \mathrm{I} & \mathrm{T}\end{array}$ GTC CCT ATT TTC CTG TTG TTA GAT AAg GAT GAg AGC AAg GTG GCA TTG GAg GAT GAT CAC ACC TAT $\begin{array}{llllllllllllllllllllll}\mathrm{V} & \mathrm{P} & \mathrm{I} & \mathrm{F} & \mathrm{L} & \mathrm{L} & \mathrm{L} & \mathrm{D} & \mathrm{K} & \mathrm{D} & \mathrm{E} & \mathrm{S} & \mathrm{K} & \mathrm{V} & \mathrm{A} & \mathrm{L} & \mathrm{E} & \mathrm{D} & \mathrm{D} & \mathrm{H} & \mathrm{T} & \mathrm{Y}\end{array}$ GAG GGT CTG GAA ATT GAC CAg ACG GCC ACC TAT GAG GAC ATC GTG ACA CTT CGG ACA GGA GAA GTA $\begin{array}{lllllllllllllllllllllll}\mathbf{E} & \mathrm{G} & \mathrm{L} & \mathrm{E} & \mathrm{I} & \mathrm{D} & \mathrm{Q} & \mathrm{T} & \mathrm{A} & \mathrm{T} & \mathrm{Y} & \mathrm{E} & \mathrm{D} & \mathrm{I} & \mathrm{V} & \mathrm{T} & \mathrm{L} & \mathrm{R} & \mathrm{T} & \mathrm{G} & \mathrm{E} & \mathrm{V}\end{array}$ AAA TGG TCA GTG GGT GAG CAC CCG GGC CAG GAG TGA

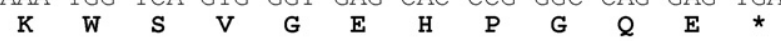

AGGGTTCCCTGACCTGGCAATCCTTCCTACGCTCCCCAGCCCTCCATCAACTTCCTGGAGGCAGCTCATCTAGCAAATCAGCTTCAT GGACCTGCTCTGGTTTCCATCCTATTACTCCTTTATCATAACTGTCCTGCCTCCAGGCATACTGACCCAGCTCCGCCTTCCTATTTC CAGTCCCTCGAGACTCACAACCATCTCCAGAGGGATGTAGGCCTGCAGTGCTTAACAGAGCACAGGTTGGGGAAGTTGTCTCTCTGA GGTTCTTTGGAGTTGGCCATGTCCATGATGGCTGGGGGAAGGAGACAGAGTAGAGGGAGACTTAGACTTAGTGGGGAGAAGGGAGAT AAGACAAAGGAAAACAGATTTGGAGTCTGGTGGGGAAAAAATGGAAGGAACCTGTAAATCTGACTCAGACTGATCTATGAGACCAGA CCATACTTGGACCTTTACAGCATCATGCCTCCAGTTTTGATGCAAGCAAAGGTCAGGATAGACTCTAAACAGTTGGCCAGCCAACTG ACTCAATCCAAATTAGGGGTTGTGGAAATATATCCCCTTCTCCCATCTCCCAGGGTCCTATTGGGCCCTTCCTGGTGTCCTGTGCAT AGCTCCTGATGTAATAAACTGTGTGTTTTGAAAAAAAAAAAAAAAAAAAAAAAAAAAA

Fig. 2. (Continued).

acids) and the first 12 amino acids of the Ig domain whilst exon 3 coded for most of the Ig domain (104 amino acids). The remainder of the Ig domain (16 amino acids), the entire transmembrane region (22 amino acids) and the first 2 amino acids of the cytoplasmic tail are encoded on exon 4 and the rest of the cytoplasmic tail is divided between exons 5 and 6 (14 amino acids and 32 amino acids, respectively). Analysis of the opossum $C D 79 b$ gene introns revealed agreement with those of other $C D 79 b$ genes including human (Hashimoto et al., 1994a), mouse (Hermanson et al., 1988), rat (Nakazato et al., 1998) and chicken (Katsukura et al., 2001) whereby introns 1-3 contain the type I (also known as phase I) splice motif and introns 4 and 5 contain the type 0 (phase 0 ) motif.

\subsection{Promoter analysis of the marsupial CD79a and $C D 79 b$ genes}

The $5^{\prime}$ flanking region upstream of the opossum and tammar CD79a and CD79b genes (Fig. 4) was analysed for known transcription factor-binding sites (Faisst and Meyer, 1992). An alignment of this region revealed a high level
(A)

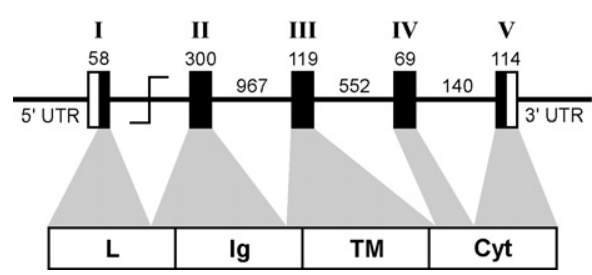

(B)

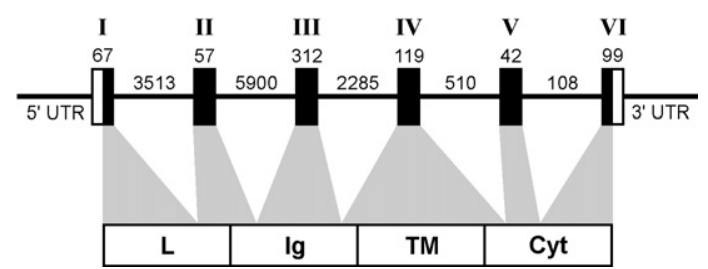

Fig. 3. Genomic organisation of the opossum $C D 79 a(\mathrm{~A})$ and $C D 79 b(\mathrm{~B})$ genes. Not drawn to scale. Exons are boxed and numbered in roman numerals whilst introns are designated by solid lines. The length of each exon and intron are indicated except for intron 1 in opossum $C D 79 a$ where the length is unknown. The structural arrangement of the protein domains in relation to coding exons (shaded areas) is also shown. L, leader; Ig, extracellular Ig domain; TM, transmembrane; CYT, cytoplasmic tail. 
(A)

\section{Opossum}

Tammar

Opossum

Tammar

Opossum

Tammar

(B)

\section{Opossum}

Tammar

Opossum
Tammar

Opossum

Tammar

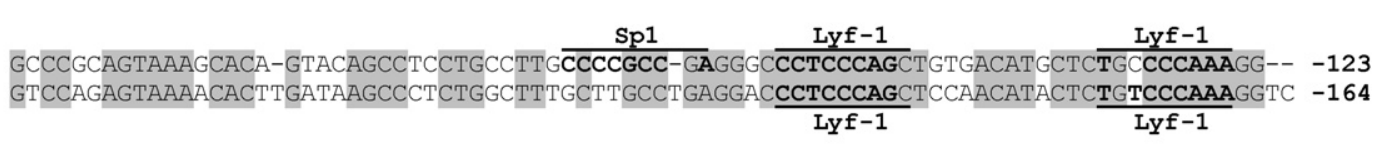

--CCCGCC---------TGTC-C---------GGAGGGCTGGCCCCGGG-AGCAGTGGAGCTCATCTCCTGGCAGGGGGCTCT TACCCAGCTCTGTTCTCTGTCTCTGGGCCCTGGGGGGGCTGGCATTGGGGGAGCAGTGGAGCTCATCTCCTATCCAGGTGC--A

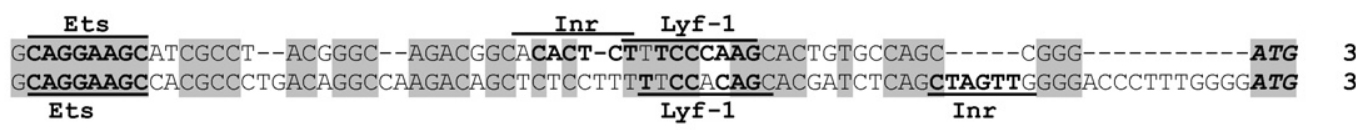

3

CCCCAAGTCTGAGCCTC̈TAGGAGTAGACAATAGAGAGTATÄCTCCA-GTATTAATCCCTTCTTTCG-CCCCACCTCCTCTACC -154 CCCCAAATCTGAGCAGCAAGGAGCAGGCAATAGAGTATGCAGCTCCCCATGTTAATCTCTTCTTTGGGCCCCACCTT-TCTACC -166

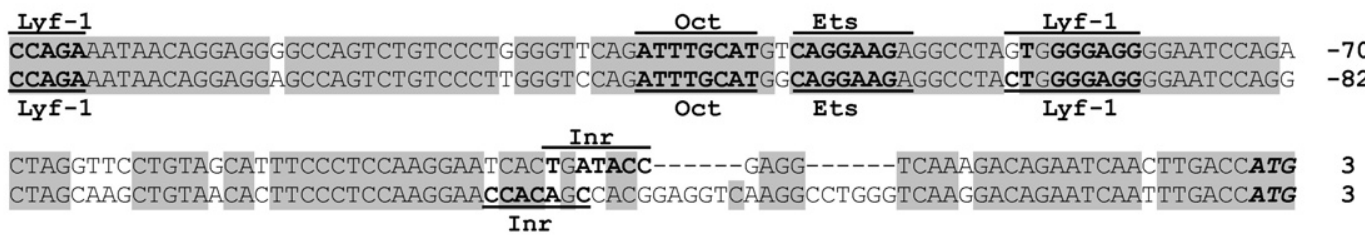

Fig. 4. Alignment of the putative promoter region in the opossum and tammar $C D 79 a(A)$ and $C D 79 b(B)$. Consensus recognition sequences of potential factor-binding sites in the promoter region are shown in bold and named above the opossum and below the tammar sequence. The ATG translation start site is shown in bold and italics.

of sequence conservation, showing $60 \%$ identity between the marsupial CD79a sequences and $79 \%$ identity between the marsupial $C D 79 b$ sequences. As with the human and murine $m b-1(C D 79 a)$ and $B 29(C D 79 b)$ genes (Ha et al., 1994; Hermanson et al., 1989; Kashiwamura et al., 1990; Thompson et al., 1996), both marsupial genes lacked a TATA box. TATA-less eukaryotic promoters commonly have multiple initiation sites for transcription. Several possible transcription initiator (Inr) consensus sequence motifs (Smale and Baltimore, 1989) were found in the marsupial sequences. For the marsupial CD79a gene, the putative Inr shown for opossum (Fig. 4A) was located in the same position as in human and mouse $m b-1$ (CD79a) (Ha et al., 1994; Kashiwamura et al., 1990), where it overlaps two of the major transcription start sites. In marsupial $C D 79 b$, the putative Inr shown for opossum and tammar (Fig. 4B) was located just upstream of the major transcription start sites in human and mouse B29 (CD79b) (Hermanson et al., 1989; Thompson et al., 1996).

Several putative transcription factor-binding sites were identified in the CD79a promoter region in both marsupials (Fig. 4A) including Ets (Bassuk and Leiden, 1997), Lyf-1 (Lo et al., 1991) and Sp1 (Wierstra, 2008). However, other motifs found in the human (Ha et al., 1994), murine (Kashiwamura et al., 1990) and bovine (Youn et al., 1997) mb-1 (CD79a) promoter regions, including EBF/BLyF (Feldhaus et al., 1992), MUF-2 (Travis et al., 1991) and NF- $\kappa$ B (Lenardo and Baltimore, 1989), were absent from the marsupial $C D 79 a$ promoter regions. In the mouse, the expression of $m b-1$ ( $C D 79 a)$ is developmentally regulated in the B cell lineage, appearing in very early B cells and mature B cells but not in plasma cells (Sakaguchi et al., 1988). It is perhaps not unexpected that the critical control element of the $m b-1(C D 79 a)$ gene in humans and mice, EBF (early B cell factor, also referred to as BLyF), has been identified in pre-B and B cells but not in plasma cells. This may be one reason for the developmentally regulated expression of the $m b-1$ (CD79a) gene during the early, but not the late, stages of B cell differentiation (Hagman et al., 1991). The absence of a binding site for EBF in the putative promoter region of the CD79a gene in both marsupials was therefore surprising. Analysis of the Ensembl Monodelphis genome revealed the opossum EBF gene on chromosome 1, upstream of the gene RNF145 as is the mouse EBF gene on chromosome 11. Based on this data, it is possible that an EBF binding site for the marsupial CD79a gene occurs in a different location to that observed in human and mouse. However, it is currently unknown if the $E B F$ gene is expressed in marsupials and further studies are required to establish the function of EBF in the regulation of the $C D 79 a$ gene in marsupials. If the $C D 79 a$ gene is developmentally regulated in the marsupials as it is in human and mouse it is likely that another regulatory mechanism may be operating.

The putative $C D 79 b$ promoter region in the tammar and opossum (Fig. 4B) contained motifs for Oct (Matthias, 1998), Ets and Lyf-1. These elements were highly conserved in sequence and position to all known mammalian B29 $(C D 79 b)$ promoter regions, including human (Thompson et al., 1996), mouse (Omori and Wall, 1993) and rat (Nakazato et al., 1998). Unlike the developmentally regulated expression of the $m b-1$ (CD79a) gene, the $B 29$ (CD79b) gene is expressed at all stages of $B$ cell differentiation including plasma cells of mice and humans. The high conservation of regulatory elements in the $B 29(C D 79 b)$ promoter region across mammals including the marsupials suggests that the marsupial $C D 79 b$ gene may also be expressed at all stages of cell differentiation in the $B$ cell lineage. 
(A)

Opossum
Tammar
Human
Mouse
Cow
Pig

- Leader

MMPG---L-SLPCALLLV----SA-LSPGSQT Id\% MMSS---L-IPPLVLLLI----SV-LNPGFLT 52 MPGGPGVLQALPATIFLLFLLSAVYLGPGCQ- 31 MPGGLEALRALPLLLFLS----YÄCLGPGCQ- 42 MPEGPQALQSPPATIFLL-LISAAGLGPGCQ- 35 MPGGRRALQTPPATIFLL-LISAAALGPCCQ- 29
Ig Domain

WALQVNPGPPSVTVPVGGIÄQLPCEHDGGPNANVTWWRVILGNFSWPKVQVVAK WGLRVEPGQPSVTVPVGGTALLHCEHDGSSDANVTWWRVNMDS FTWPRKKVEK -ALWMHKVPASLMVS LGEDAHFQCPHNSSNNANVTWWR I LHGNY TWPPEFLGP -ALRVEGGPPSLTVNLGEEARLTCENNG-RNPNITWWESLQSNITWPPVPLGP -ALWVEWGPPSVTVSVGEEVRLQCTHNG-SNTNVTWWHVLQSNSSWPPVMYRG -ALWVDWGPPSVTVSVGDKVSLPCRHNS-NSTNI TWWRVPQGNSTWPPVMDLS *

Tammar FIHPNGTLVILAANKSDGGMYLCQVSVENDQASESCGTYLRVREPIPRPFLDMGEGTKNR 66 Human GEDPNGTLIIQNVNKSHGGIYVCRVQEGNESYQQSCGTYLRVRQPPPRPFLDMGEGTKNR 51 Mouse GQGTTGQLFFPEVNKNTGACTGCQVIEN-NILKRSCGTYLRVRNPVPRPFLDMGEGTKNR 48 COW DVGAGGELIIKPVNKTHRGMYRCQVSDG-KKIQRSCGTYLRVRDPLPRPFLDMGEGTKNN 53 Pig ELGPKGELIIQQVNKSHRGMYRCEVNEG-QRIQRSCGTYLRVRDPLPRPFLDMGEGTKNN 53 FRKRWONEKLGLDAGDEYEDENLYEGLNLDDCSMYEDISRGLQGTYODVGSLNIGDVQLEKP 79 Mouse FRKRWQNEKFGVDMPDDYEDENLYEGLNLDDCSMYEDISRGLQGTYQDVGNLHIGDAQLEKP 79 COW FRKRWQNMKFGADIQDDYEDENLYEGLNLDDCSMYEDISRGLQGTYQDVGSLHIGDAQLEKP 75 Pig FRKRWQNVKFGADVQDDYDDENLYEGLNLDDCSMYEDISRGLQGTYQDVGSLHIGDVQLEKP 79

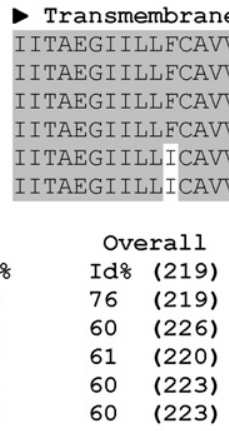

\section{(B)}

Opossum

Tammar

Human

Mouse

Norway rat

Chicken
- Leader

MAGLGLPTIFKEGLGVLLLIFSAGEM Id\% MAGLGLPTISKEGLRVLLLILS-GEM 84 MARLALSPVPSHWMVALLLLLS-AEP 34 MATLVLSSMPCHWLLFLLLLFS-GEP 46 MATLVLSPVPCHWLMFLLLLLS-GEP 42 MGDFC-RRLWVLQVNLWLMAVAAGG- 15

\section{- Ig Domain}

VLGSQT IE-EAIPESRGNTCTKLWQYPRFMAKKRDSSFSVTCHVN-GYGQVTWLR ILKVQTANGDVVQASRANSCSKLWQRLRFVAKKRDSS FEVTCHVE-HPREVTWLV VPAARSED--RYRNPKGSACSRIWOSPRFIARKRGFTVKMHCYMNSASGNVSWLW VPAMTSSD--LPLNFQGSPCSQIWQHPRFAAKKRSSMVKEHCYTN-HSGALTWFR VPAMTKSD--QPPIFQGSPCSKIWQHPRFAAKKRSSMVKFHCHTD-YSGVMTWFR IPTDGNST----SNRTGSECVGMWQHPRYIAAKKNTSVHFICYTS-QPHAMQWYK

\begin{tabular}{|c|c|c|c|c|}
\hline Opossum & \multicolumn{2}{|c|}{ KQESDASPQVLKTNNGQIVESRNGSTLTLTIQKIQFEDNGIYYC̈QQVCMDNPNKI FQGCGTELRVMGYSTVAQLKRRNTLKD } & \multicolumn{2}{|c|}{ Id\% } \\
\hline Tammar & \multicolumn{2}{|c|}{ KRESDLVPQALPPDNGRLRRVTNNNTATLI ITKIQFEDNGIYYCEEKCMEGPRENLRGCGTELRVMGFSTMAQLKRRNTLKD } & \multicolumn{2}{|c|}{60} \\
\hline Human & \multicolumn{2}{|c|}{ KQEMDENPQQLKLEKGRMEESQNESLATLTIQGIRFEDNGIYFCQQKCNNTS-EVYQGCGTELRVMGFSTLAQLKQRNTLKD } & \multicolumn{2}{|l|}{51} \\
\hline louse & \multicolumn{2}{|c|}{ KRGS-QQPQELVSEEGR IVQTQNGSVYTLTIQNIQYEDNGIYFCKQKCDSANHNVTDSCGTELLVLGFSTLDQLKRRNTLKD } & \multicolumn{2}{|l|}{48} \\
\hline Norway rat & \multirow{2}{*}{\multicolumn{2}{|c|}{$\begin{array}{l}\text { QKGN-QRPQELFPEDGHISQTRNGSVYTLTLQNIQYEDNGIY FCQQKCNSTEPDVTDGCGTELLVLGFSTLDQLKRRNTLKD } \\
\text { ALGNGKEFHVLDQSSDRFS INNTNDRISFT ISRISYEDNGIYVCDSKNLTEEKRQPNSCGTEIRVMSRSNIQQIQNRNTLKD }\end{array}$}} & \multicolumn{2}{|l|}{48} \\
\hline \multirow[t]{3}{*}{ Chicken } & & & \multirow{2}{*}{\multicolumn{2}{|c|}{28}} \\
\hline & & & & \\
\hline & - Transmembrane & - Cytoplasmic & \multicolumn{2}{|c|}{ Overall } \\
\hline Dpossum & AIMIQTLLIIVFITVPVFLLL Id & DKDDNKVVLEDDHTYEGLEIDQTATYEDIVTLRTGEVKWSVGEHPGQE & Id $\%$ & (231) \\
\hline Human & IILFIIVPIFLLL 81 & LDIDQTATYEDIVTLRTGEVKWSVGEHPGQE 87 & 59 & (229) \\
\hline Mouse & LIILFIIVPIFLLL 77 & LNIDQTATYEDIVTLRTGEVKWSVGEHPGQE & 58 & $(228)$ \\
\hline Norway rat & IILFIIVPIFLLL 81 & LNIDQTATYEDIVTLRTGEVKWSVGEHPGQE 87 & 59 & $(228)$ \\
\hline Chicken & TIIIQTILLVIFISVPMLLFL 54 & EKGDRKERPEEDHTYEGLEVEQIATYEDITPFRDMKAKWTVGEHPGEE 60 & 35 & (226) \\
\hline
\end{tabular}

Fig. 5. Alignment of the CD79a (A) and CD79b (B) amino acid sequence of opossum with other vertebrates (including tammar) showing the level of sequence identity (Id\%) with the opossum sequences. The alignment was generated using ClustalW (BioManager) and identical residues ( $>60 \%$ ) are shaded. Dashes indicate gaps introduced into the sequence to optimise the alignment. The leader sequence, Ig domain, transmembrane region and cytoplasmic tail boundaries indicated above the sequences were predicted using Interproscan with the exception that the CD79b leader sequence length was based on the human and mouse CD79b sequence due to discrepancies in the length of the SignalP predicted marsupial CD79b leader sequences. The extracellular cysteines are indicated with an asterisk whilst the potential N-linked glycosylation sites in the extracellular domain are shown in bold. Features of note in the cytoplamsic tail are the ITAM consensus motifs that are underlined, the peptide sequence of the anti-human CD79a antibody and the peptide sequence of the anti-human CD79b antibody that are shown in bold. GenBank accession numbers are as follows: Human (CD79a, M74721; CD79b, S52229), Mouse (CD79a, X13450; CD79b, J03857), Cow (CD79a, D16412) and Pig (CD79a, AM915272), Norway rat (CD79b, AB004831) and Chicken (CD79b, AB062512).

\subsection{Comparison of the marsupial CD79 deduced protein sequences with their homologs in other species}

A multiple alignment of the marsupial CD79a and CD79b deduced amino acid sequences with other known CD79 sequences is shown in Fig. 5, and illustrates the level of sequence identity with the opossum CD79a (Fig. 5A) and CD79b (Fig. 5B) sequences. Highest overall identity was observed between the marsupial sequences, showing identities of $76 \%$ (CD79a) and 72\% (CD79b) whilst identity with their eutherian homologs was 60-61\% (CD79a) and 58-59\% (CD79b). For the structural domains, the signal peptide and extracellular domain of the CD79a and CD79b sequences were poorly conserved across species examined. This was particularly evident for the leader sequence of the CD79a sequences, which revealed 52\% identity between the marsupial sequences whilst identity with the eutherian CD79a leader sequences ranged from $42 \%$ (mouse) to 29\% (pig).

Despite the low level of sequence conservation in the extracellular domains of CD79a (48-66\%) and CD79b (48-60\%) amongst mammals, the structural features of this domain were conserved in the opossum and tammar. The extracellular domain of opossum and tammar CD79a 
revealed the presence of three conserved cysteine residues. The two cysteines (C-50, C-101 in mouse) capable of forming an intrachain bond in the Ig fold of this domain were conserved, as was the membrane proximal cysteine (C113 in mouse) capable of intermolecular dimer formation between the CD79a and CD79b subunits of the BCR, as seen in human and mouse CD79a (Sakaguchi et al., 1988; Yu and Chang, 1992). The number of $\mathrm{N}$-linked glycosylation motifs (NX[T/S], where $X$ is any residue except proline) in eutherian CD79a sequences varies considerably. There are six motifs present in human CD79a and two predicted sites in the mouse whilst the cow and pig both have four predicted N-linked glycosylation sites. There were three potential $\mathrm{N}$-linked glycosylation sites in both the opossum and the tammar CD79a sequences that were each conserved in their positioning in relation to their mammalian counterparts (see Fig. 5A).

The extracellular domain of opossum and tammar CD79b contained five conserved cysteine residues. In these sequences, there are two potential sites for disulphide linkage between the first four cysteines (C-43, C-65, C-120, $\mathrm{C}-124$ in mouse) that would involve a canonical disulphide linkage of the Ig fold between cysteine residues C-65 and $\mathrm{C}-120$ (in mouse) and an additional covalent bond between cysteine residues $\mathrm{C}-43$ and $\mathrm{C}-124$ (in mouse). Moreover, the membrane proximal cysteine (C-135 in mouse) capable of dimerisation between the two subunits was conserved as in human and mouse CD79b (Hashimoto et al., 1993; Hermanson et al., 1988; Siegers et al., 2006). For N-linked glycosylation sites, the human and mouse CD79b sequences each have three potential sites, there are two possible sites in the rat whilst the chicken has 5 potential $\mathrm{N}$-linked glycosylation sites. In the opossum and tammar CD79b sequences a single $\mathrm{N}$-glycosylation site was observed in both marsupial sequences at one of the sites common to all known CD79b sequences in vertebrates (see Fig. 5B).

The transmembrane region has remained highly conserved during evolution, with identities as high as $100 \%$ (CD79a) and 90\% (CD79b) between the marsupials and ranging from 95-100\% (CD79a) and 77-81\% (CD79b) between the marsupials and eutherians. This high sequence conservation is not surprising since the transmembrane region of the CD79 subunits are known to be critical for the formation of heterodimers during the assembly of the BCR complex (Dylke et al., 2007). Of note are two polar residues that are conserved across all known CD79 molecules, namely glutamic acid in CD79a (E-148 in human) and glutamine in CD79b (Q-165 in human), that potentially form strong ionic and hydrogen bonds thus stabilising the heterodimer (Dylke et al., 2007).

The high conservation of the cytoplasmic tail amongst mammals (CD79a, 75-96\%; CD79b, 87-93\%) reflects the presence of a conserved regulatory motif in this region, the ITAM $\left(\mathrm{D} / \mathrm{E}(\mathrm{x})_{7} \mathrm{D} / \mathrm{Exx} Y \mathrm{xxL}(\mathrm{x})_{7} \mathrm{YxxI} / \mathrm{L}\right)$ (Reth, 1989). This motif is conserved in the marsupial CD79a and CD79b sequences. In mammals, phosphorylation of the ITAM tyrosine residues on the CD79a and CD79b subunits promotes the recruitment and activation of the Syk tyrosine kinase that binds through its tandem $\mathrm{SH} 2$ domains to the paired phospho-tyrosines in the ITAM (Dal Porto et al., 2004; Gold,
2002). In addition to the ITAM tyrosines, there are two additional tyrosine residues (Y-176, Y-204 in mouse) in mammalian CD79a including the marsupials. Phosphorylation of the residue at position 204, recruits the B cell linker protein BLNK that binds through its $\mathrm{SH} 2$ domain thus forming a platform for downstream signaling pathways (Engels et al., 2001; Kabak et al., 2002).

Despite the clear structural homology between the CD79a and CD79b subunits, they are not closely related to each other, with amino acid identities being as low as $21 \%$ (human), 18\% (opossum, tammar) and 17\% (mouse). This is also evident in the phylogenetic tree based on the amino acid alignment (Fig. 6) where the marsupial CD79a and CD79b sequences are each more closely related to their eutherian homologs than they are to each other and, as such, form two distinct clusters. Within the CD79a and CD79b clusters, the marsupial sequences form a monphyletic clade as a sister group to the eutherians.

\subsection{Tissue-specific distribution of CD79a and CD79b in adult and pouch young marsupials}

The tissue-specific profile of CD79a and CD79b in the tissues of adult and pouch young marsupials has previously been analysed using anti-human CD79a and anti-human CD79b antibodies by immunohistochemistry (Hemsley et al., 1995; Old and Deane, 2003; Old et al., 2004). These antibodies have shown wide cross-reactivity in mammals including the mouse, rat, pig and cow as well as chicken (Jones et al., 1993) but the results in marsupials have been variable. Despite the fact that the anti-human CD79b antibody showed good staining in the tissues of a broad range of marsupials, the anti-human CD79a antibody showed no reactivity in most marsupials including the tammar, opossum, koala, ringtail possum and eastern gray kangaroo (Hemsley et al., 1995; Jones et al., 1993; Old and Deane, 2001). This lack of reactivity can be explained by the sequence data presented in this study. The marsupial CD79b sequences are $100 \%$ identical to the anti-human CD79b peptide sequence ( 15 residues) whilst both the marsupial CD79a sequences have a mismatch of 5 residues at positions $6,7,8,10$ and 11 to the peptide sequence (14 residues) of anti-human CD79a (Fig. 5).

The expression profile of CD79a and CD79b transcripts in the tissues of adult opossum and tammar was analysed by RT-PCR and resulted in a similar tissue expression pattern in both marsupials (Fig. 7). CD79a and CD79b transcripts were expressed in the spleen, liver, heart and gut of both marsupials, as well as the blood in the tammar and the lung in the opossum. A low level of expression was detected in the kidneys of the tammar. Transcripts were not observed in the opossum kidney or the brain of either marsupial. In addition, RT-PCR analysis of the expression of CD79a and CD79b transcripts in the tammar pouch young tissues was performed (Fig. 8). CD79a and CD79b transcripts were detected in the bone marrow, cervical thymus and lung at day 10 postpartum. However, although CD79a transcripts were expressed in the spleen and blood at day 10, CD79b transcripts were not detected in these tissues until day 21 postpartum. The gut showed either no expression or a very low level of expression at all ages tested. 


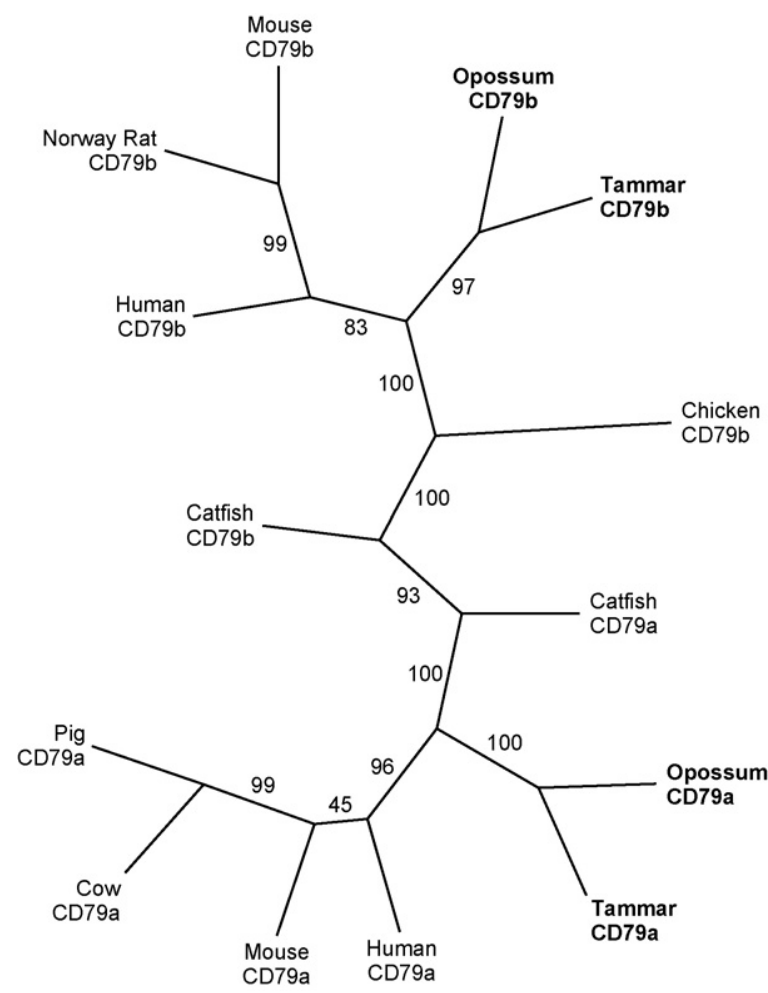

Fig. 6. Phylogenetic analysis of vertebrate CD79a and CD79b amino acid sequences showing the marsupial sequences in bold. The complete coding sequences were used in the construction of the tree. Bootstrap values are out of 100. Additional GenBank accession numbers not mentioned elsewhere are as follows: Catfish (CD79a, EF173897; CD79b, EF173898).

By day 120 postpartum, the CD79a and CD79b transcripts were expressed at a high level in the lymphoid organs including the bone marrow, cervical thymus and spleen as well as the blood.

A previous analysis of the distribution of $\mathrm{CD} 79 \mathrm{~b}^{+}$cells in the tissues of tammar pouch young by immunohistochemistry using the anti-human CD79b antibody (Old and Deane, 2003) showed CD79b ${ }^{+}$cells in the spleen at day 21 postpartum and the thymus at day 23 postpartum, but cells were not detected in the bone marrow, gut (except one sample at day 7 postpartum) or lung $\left(\mathrm{CD} 79 \mathrm{~b}^{+}\right.$cells were observed

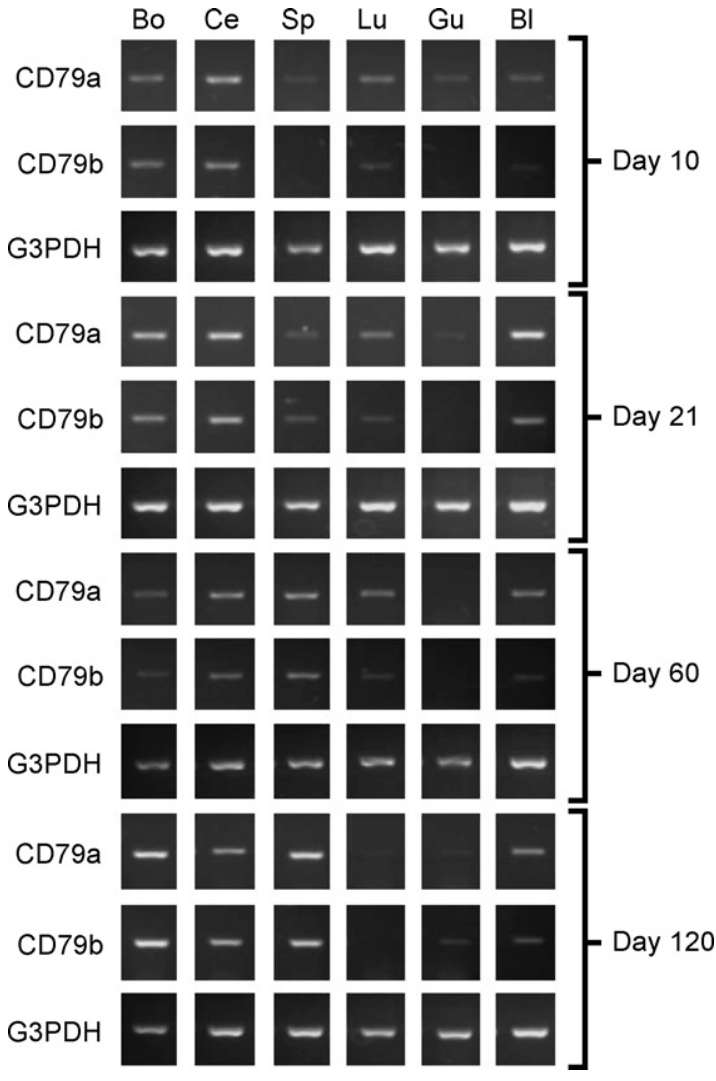

Fig. 8. RT-PCR analysis of CD79a and CD79b transcripts in the tissues of tammar pouch young at days $10,21,60$ and 120 postpartum. Tissues analysed were: bone marrow (Bo) cervical thymus (Ce), spleen (Sp), lung (Lu), gut $(\mathrm{Gu})$ and blood (Bl). Expression of G3PDH was included as an internal control. Tissues from two individuals were analysed for each age group with only one result shown.

in the blood vessels of the lung) at any age. With the exception of the bone marrow, these results are consistent with those presented here and suggest that a functional BCR may not be assembled until day 21 postpartum, when the expression of CD79b is evident. As a result, tammar neonates younger than 21 days old may not be capable of mounting an effective adaptive immune response. Further studies are necessary to resolve the apparent discrepancy
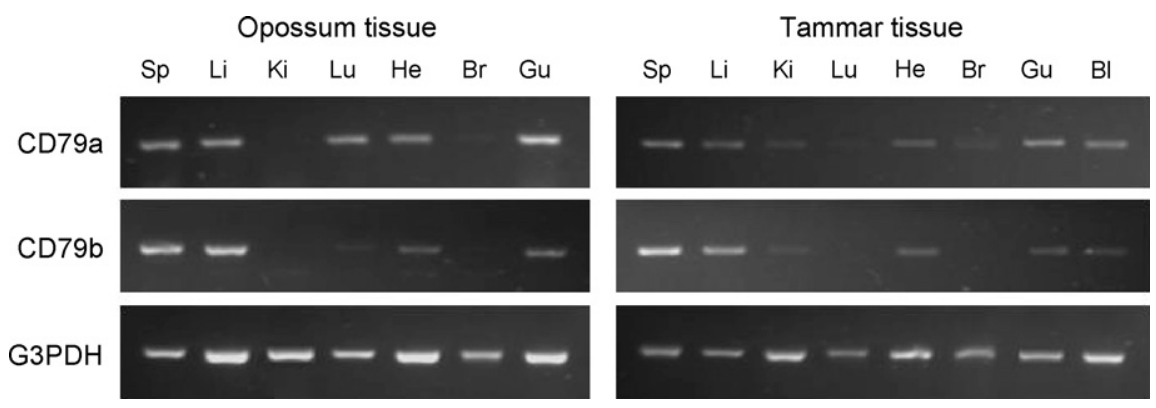

Fig. 7. Expression profile of CD79a and CD79b transcripts in adult opossum and the tammar wallaby tissues. Tissues analysed were: spleen (Sp), liver (Li), kidney (Ki), lung ( $\mathrm{Lu})$, heart ( $\mathrm{He})$, brain ( $\mathrm{Br})$, gut ( $\mathrm{Gu})$ and blood (Bl). Expression of G3PDH was included as an internal control. Tissues samples were tested in duplicate with only one result shown. 
in the mRNA and protein expression of CD79b in the bone marrow.

\section{Conclusion}

Whilst whole genome sequence data provides a valuable tool for the isolation of homologous genes in divergent species, confirmation of these gene sequences by cDNA or genomic cloning is often necessary to identify the correct exon/intron boundaries and the $5^{\prime}$ and $3^{\prime}$ ends of genes. Moreover, orientation errors can arise in the assembly of the genome as seen for the opossum CD79a gene presented here. In this study, a combination of bioinformatics and laboratory based molecular protocols were used. We initially analysed the opossum genome sequence data to identify the $C D 79 a$ and $C D 79 b$ genes and then used this data to facilitate the isolation of CD79a and CD79b cDNA transcripts in the opossum and the tammar wallaby. This data provides valuable molecular information on the CD79 subunits in marsupials and will allow further investigation of the role of B cell signaling in the marsupial immune system.

\section{Acknowledgements}

The authors would like to thank Norman Saunders and Kate Dziegielewska (Department of Pharmacology, University of Melbourne, Vic) for supplying the opossum tissue and Lyn Hinds (CSIRO, Division of Entomology, Canberra) for supplying the tammar wallaby tissue. We also thank the Macquarie University Fauna Park staff for their assistance in animal handling. LD was supported by a Macquarie University Postgraduate award.

\section{References}

Ales-Martinez, J.E., Cuende, E., Martinez-A, C., Parkhouse, R.M.E., Pezzi, L., Scott, D.W., 1991. Signalling in B cells. Immunol. Today 12, 201-205.

Bassuk, A.G., Leiden, J.M., 1997. The role of Ets transcription factors in the development and function of the mammalian immune system. Adv. Immunol. 64, 65-104.

Bennani-Baiti, I.M., Cooke, N.E., Liebhaber, S.A., 1998. Physical linkage of the human growth hormone gene cluster and the CD79b $(\operatorname{Ig} \beta / B 29)$ gene. Genomics 48, 258-264.

Dal Porto, J.M., Gauld, S.B., Merrell, K.T., Mills, D., Pugh-Bernard, A.E., Cambier, J., 2004. B cell antigen receptor signaling 101. Mol. Immunol. 41, 599-613.

Deane, E.M., Cooper, D.W., 1988. Immunological development in pouch young marsupials. In: Tyndale-Biscoe, C.H., Janssens, P.A. (Eds.), The Developing Marsupial. Models for Biomedical Research. SpringerVerlag, Berlin.

DeFranco, A.L., 1993. Structure and function of the B cell antigen receptor Annu. Rev. Cell Biol. 9, 377-410.

Duncan, L.G., Nair, S.V., Deane, E.M., 2007. Molecular characterisation and expression of CD4 in two distantly related marsupials: the gray short-tailed opossum (Monodelphis domestica) and tammar wallaby (Macropus eugenii). Mol. Immunol. 44, 3641-3652.

Duncan, L.G., Nair, S.V., Deane, E.M., 2009. The marsupial CD8 gene locus: molecular cloning and expression analysis of the alpha and beta sequences in the gray short-tailed opossum (Monodelphis domestica) and the tammar wallaby (Macropus eugenii). Vet. Immunol Immunopathol. 129, 14-27.

Dylke, J., Lopes, J., Dang-Lawson, M., Machtaler, S., Matsuuchi, L., 2007. Role of the extracellular and transmembrane domain of Ig- $\alpha / \beta$ in assembly of the B cell antigen receptor (BCR). Immunol. Lett. 112, 47-57.

Engels, N., Wollscheid, B., Wienands, J., 2001. Association of SLP-65/BLNK with the B cell antigen receptor through a non-ITAM tyrosine of Ig- $\alpha$. Eur. J. Immunol. 31, 2126-2134.

Faisst, S., Meyer, S., 1992. Compilation of vertebrate encoded transcription factors. Nucleic Acids Res. 20, 3-26.
Feldhaus, A.L., Mbangkollo, D., Arvin, K.L., Klug, C.A., Singh, H., 1992. BLyF, a novel cell-type- and stage-specific regulator of the B-lymphocyte gene mb-1. Mol. Cell. Biol. 12, 1126-1133.

Felsenstein, J., 1989. PHYLIP: phylogeny Inference Package (version 3.2). Cladistics 5, 164-166.

Gold, M.R., 2002. To make antibodies or not: signaling by the B-cell antigen receptor. Trends Pharmacol. Sci. 23, 316-324.

Guselnikov, S.V., Najakshin, A.M., Taranin, A., 2003. Fugu rubripes possesses genes for the entire set of the ITAM-bearing transmembrane signal subunits. Immunogenetics 55, 472-479.

Ha, H., Barnoski, B.L., Sun, L., Emanuel, B.S., Burrows, P.D., 1994. Structure, chromosomal localization, and methylation pattern of the human mb1 gene. J. Immunol. 152, 5749-5757.

Hagman, J., Travis, A., Grosschedl, R., 1991. A novel lineage-specific nuclear factor regulates mb-1 gene transcription at the early stages of B cell differentiation. EMBO J. 10, 3409-3417.

Hashimoto, S., Chiorazzi, N., Gregersen, P.K., 1994a. The complete sequence of the human CD79b (Ig beta/B29) gene: identification of a conserved exon/intron organization, immunoglobulin-like regulatory regions, and allelic polymorphism. Immunogenetics 40 , 145-149.

Hashimoto, S., Gregersen, P.K., Chiorazzi, N., 1993. The human Ig- $\beta$ cDNA sequence, a homologue of murine B29, is identical in B cell and plasma cell lines producing all the human Ig isotypes. J. Immunol. 150, 491-498.

Hashimoto, S., Mohrenweiser, H.W., Gregersen, P.K., Chiorazzi, N., 1994b. Chromosomal localization, genomic structure, and allelic polymorphism of the human CD79 alpha (Ig-alpha/mb-1) gene. Immunogenetics 40, 287-295.

Hemsley, S.W., Canfield, P.J., Husband, A.J., 1995. Immunohistological staining of lymphoid tissue in four Australian marsupial species using species cross-reactive antibodies. Immunol. Cell Biol. 73, 321-325.

Hermanson, G.G., Briskin, M., Sigman, D., Wall, R., 1989. Immunoglobulin enhancer and promoter motifs 5' of the B29 B-cell-specific gene. Proc. Natl. Acad. Sci. U.S.A. 86, 7341-7345.

Hermanson, G.G., Eisenberg, D., Kincade, P.W., Wall, R., 1988. B29: a member of the immunoglobulin gene superfamily exclusively expressed on B-lineage cells. Proc. Natl. Acad. Sci. U.S.A. 85, 6890-6894.

Jones, M., Cordell, J.L., Beyers, A.D., Tse, A.G.D., Mason, D.Y., 1993. Detection of $\mathrm{T}$ and $\mathrm{B}$ cells in many animal species using cross-reactive anti-peptide antibodies. J. Immunol. 150, 5429-5435

Kabak, S., Skaggs, B.J., Gold, M.R., Affolter, M., West, K.L., Foster, M.S. Siemasko, K., Chan, A.C., Aebersold, R., Clark, M.R., 2002. The direct recruitment of BLNK to immunoglobulin- $\alpha$ couples the B-cell antigen receptor to distal signaling pathways. Mol. Cell. Biol. 22, 2524-2535.

Kashiwamura, S.-I., Koyama, T., Matsuo, T., Steinmetz, M., Kimoto, M. Sakaguchi, N., 1990. Structure of the murine mb-1 gene encoding putative sIgM-associated molecule. J. Immunol. 145, 337-343.

Katsukura, H., Murakami, R., Chijiiwa, Y., Otsuka, A., Tanaka, M., Nakashima, K., Ono, M., 2001. Structure of the $\beta$-chain (B29) gene of the chicken B-cell receptor and conserved collinearity with genes for potential skeletal muscle sodium channel and growth hormone. Immunogenetics 53, 770-775.

Kozak, M., 1983. Comparison of initiation of protein synthesis in prokaryotes, eukaryotes and organelles. Microbiol. Rev. 47, 1-45.

Lee, S.J., Kim, S.J., Park, C.-G., Park, J., Kim, J.H., Chun, T., 2008. Molecular cloning and expression analysis of pig CD79a. Vet. Immunol. Immunopathol. 125, 368-374.

Lenardo, M.J., Baltimore, D., 1989. NF-кB: a pleiotropic mediator of inducible and tissue-specific gene control. Cell 58, 227-229.

Lo, K., Landau, N.R., Smale, S.T., 1991. LyF-1, a transcriptional regulator that interacts with a novel class of promoters for lymphocyte-specific genes. Mol. Cell. Biol. 11, 5229-5243.

Matsuuchi, L., Gold, M.R., Travis, A., Grosschedl, R., DeFranco, A.L., Kelly, R.B., 1992. The membrane IgM-associated proteins mb- 1 and Ig- $\beta$ are sufficient to promote surface expression of a partially functional Bcell antigen receptor in a nonlymphoid cell line. Proc. Natl. Acad. Sci. U.S.A. 89, 3404-3408.

Matthias, P., 1998. Lymphoid-specific transcription mediated by the conserved octamer site: who is doing what? Semin. Immunol. 10, $155-163$.

Mikkelsen, T.S., Wakefield, M.J., Aken, B., Amemiya, C.T., Chang, J.L., Duke, S., Garber, M., Gentles, A., Goodstadt, L., Heger, A., Jurka, J., Kamal, M. Mauceli, E., Searle, S.M.J., Sharpe, T., Baker, M.L., Batzer, M.A., Benos, P.V., et al., 2007. Genome of the marsupial Monodelphis domestica reveals innovation in non-coding sequences. Nature 447, 167-177.

Nakazato, S., Nomoto, K., Kazahari, K., Ono, M., 1998. Physical linkage of the B29/Ig- $\beta$ (CD79b) gene to the skeletal muscle, sodium-channel, 
and growth hormone genes in rat and human. Genomics 48, 363368.

Old, J.M., Deane, E.M., 2001. Histology and immunohistochemistry of the gut-associated lymphoid tissue of the eastern grey kangaroo, Macropus giganteus. J. Anat. 199, 657-662.

Old, J.M., Deane, E.M., 2003. The detection of mature T- and B-cells during development of the lymphoid tissues of the tammar wallaby (Macropus eugenii). J. Anat. 203, 123-131.

Old, J.M., Selwood, L., Deane, E.M., 2004. The appearance and distribution of mature T and B cells in the developing immune tissues of the stripefaced dunnart (Sminthopsis macroura). J. Anat. 205, 25-33.

Omori, S.A., Wall, R., 1993. Multiple motifs regulate the B-cell-specific promoter of the B29 gene. Proc. Natl. Acad. Sci. U.S.A. 90, 11723-11727.

Page, R.D.M., 1996. TREEVIEW: an application to display phylogenetic trees on personal computers. Comput. Appl. Biosci. 12, 357-358.

Poole, W.E., Simms, N.G., Wood, J.T., Lubulwa, M., 1991, Tables for age determination of the Kangaroo Island Wallaby (Tammar), Macropus eugenii, from body measurements, In: Technical Memorandum No. 32, CSIRO Division of Wildlife and Ecology, Canberra.

Reth, M., 1989. Antigen receptor tail clue. Nature 338, 383-384.

Reth, M., 1992. Antigen receptors on B lymphocytes. Annu. Rev. Immunol. 10, 97-121.

Reth, M., Hombach, J., Wienands, J., Campbell, K.S., Chien, N., Justement, L.B., Cambier, J.C., 1991. The B-cell antigen receptor complex. Immunol. Today 12, 196-201.

Sahoo, M., Edholm, E.-S., Stafford, J.L., Bengten, E., Miller, N.W., Wilson, M., 2008. B cell receptor accessory molecules in the channel catfish, Ictalurus punctatus. Dev. Comp. Immunol. 32, 1385-1397.

Sakaguchi, N., Kashiwamura, S.-I., Kimoto, M., Thalmann, P., Melchers, F., 1988. B lymphocyte lineage-restricted expression of $\mathrm{mb}-1$, a gene with CD3-like structural properties. EMBO J. 7, 3457-3464.
Siegers, G.M., Yang, J., Duerr, C.U., Nielsen, P.J., Reth, M., Schamel, W.W.A., 2006. Identification of disulfide bonds in the Ig- $\alpha / \operatorname{Ig}-\beta$ component of the B cell antigen receptor using the Drosophila S2 cell reconstitution system. Int. Immunol. 18, 1385-1396.

Smale, S.T., Baltimore, D., 1989. The "initiator" as a transcription control element. Cell 57, 103-113.

Thompson, A.A., Wood, W.J., Gilly, M.J., Damore, M.A., Omori, S.A., Wall, R., 1996. The promoter and $5^{\prime}$ flanking sequences controlling human B29 gene expression. Blood 87, 666-673.

Travis, A., Hagman, J., Grosschedl, R., 1991. Heterogeneously initiated transcription from the pre-B- and B-cell-specific mb-1 promoter: analysis of the requirement for upstream factor-binding sites and initiation site sequences. Mol. Cell. Biol. 11, 5756-5766.

Tyndale-Biscoe, H., 2005. Life of Marsupials. CSIRO Publishing, Victoria.

Wierstra, I., 2008. Sp1: emerging roles-beyond constitutive activation of TATA-less housekeeping genes. Biochem. Biophys. Res. Commun. 372, $1-13$.

Wood, W.J., Thompson, A.A., Korenberg, J., Chen, X.-N., May, W., Wall, R., Denny, C.T., 1993. Isolation and chromosomal mapping of the human immunoglobulin-associated B29 gene (IGB). Genomics 16, 187-192.

Youn, H.-Y., Cho, K.-W., Nishimura, Y., Goitsuka, R., Watari, T., Tsujimoto, H., Hasegawa, A., 1997. Genomic structure of the bovine mb-1 gene encoding the Ig- $\alpha$ subunit of the B cell antigen receptor complex. Vet. Immunol. Immunopathol. 56, 247-257.

Youn, H.-Y., Goitsuka, R., Kato, H., Mason, D.Y., Watari, T., Tsujimoto, H., Hasegawa, A., 1996. Molecular cloning of bovine mb-1 cDNA. Vet. Immunol. Immunopathol. 52, 191-200.

Yu, L.-M., Chang, T.W., 1992. Human mb-1 gene: complete cDNA sequence and its expression in B cells bearing membrane Ig of various isotypes. J. Immunol. 148, 633-637. 